\title{
Effects of wheat residue and depth-control mechanism of no-till seeder on corn sowing performance
}

\author{
Rui Zhang ${ }^{1,2}$, Jiantao $\mathrm{Wei}^{3}$, Dongxing Zhang ${ }^{1,4}$, Tao Cui ${ }^{1,4}$, Bingxin Yan', Xiantao He', Dandan Han', \\ Li Yang ${ }^{1,4 *}$ \\ ${ }^{1}$ China Agricultural University, College of Engineering, Beijing, 100083, China, ${ }^{2}$ Qingdao Agricultural University, College of Mechanical- \\ Electronic Engineering, Qingdao, 266109, China, ${ }^{3} \mathrm{CNH}$ Industrial, Chicago, 60527, USA, ${ }^{4}$ Key Laboratory of the Soil-Machine-Plant \\ Technology of the Agriculture Ministry of China, China
}

\section{A B S T R A C T}

No-till planting can promote soil and water conservation and has gradually been adopted on the North China Plain where an annual wheatcorn double cropping system serves as the main cropping system. Corn is planted in June immediately after the winter wheat harvest so that fields are covered with wheat residues. The presence of wheat straw makes it difficult to maintain uniform corn seed spacing and sowing depth. To overcome these problems, a new seeder unit has been developed with a depth-control mechanism on a single-sided gauge wheel. A study was conducted to compare the performance of this seeder unit with two conventional seeder units (with depthcontrol mechanisms using double-sided gauge wheels and a rear gauge wheel) by testing in fields with two different amounts of residue $\left(0.78 \mathrm{~kg} / \mathrm{m}^{2}\right.$ and $\left.0.64 \mathrm{~kg} / \mathrm{m}^{2}\right)$. Seed spacing, sowing depth, and emergence time were measured after planting. The results indicate that the newly designed seeder unit with a single-sided gauge wheel performs better on seed spacing, sowing depth and emergence time uniformity, particularly in fields with a small amount of residue, with the quality of feed index, quality of sowing depth index and quality of emergence time index of $91.90 \%, 95.45 \%$ and $87.87 \%$, respectively. The new seeder unit can meet the requirements of no-till planting for corn.

Keywords: Corn; No-till planting; Precision; Sowing depth; Uniform emergence

\section{INTRODUCTION}

Precision seeders can save seed costs and labor while ensuring the uniformity of seed spacing and sowing depth. Plant spacing uniformity and emergence rate are the most common characteristics used by producers to evaluate planting performance (Staggenborg et al., 2004). Krall et al. (1977) reported that a reducing in the variability of row seed spacing resulted in consistent increases in yield. In addition, planting at the correct sowing depth was another important planting target which could be used to check the precision of a seeder. For example, uniform crop emergence can be achieved when using a consistent sowing depth (Chen et al., 2004). As the sowing depth for corn increased from $2.5 \mathrm{~cm}$ to $7.5 \mathrm{~cm}$, the emergence time increased by about 3 days and the final yield was reduced (Krall et al., 1977). Meanwhile, yields decreased with increased variability in sowing depth (Gan and Stobbe, 1995).

Studies have proven that no-till planting reduces soil erosion, avoids groundwater consumption by decreasing the need for irrigation, increases soil fertility and improves environmental conditions (Hendrix et al., 1998; Van Donk et al., 2010). Especially on the North China Plain where the main cropping system is an annual wheat-corn double cropping system, no-till planting can simplify the production process and lengthen crop growth time (Gao et al., 2003). Residues negatively affect planting performance by blocking furrow openers and other parts of a seeder, preventing seed drop into the furrow; this negatively affects planting efficiency and seeding quality (Çelik, 2009). Moreover, the presence of crop residues makes a uniform sowing depth difficult to maintain. The ability of the seeder to pass through residue and maintain a uniform sowing depth should be the highest priority when designing a notill precision seeder.

Achieving an accurate sowing depth can be realized with use of a row unit control mechanism. Planting units using a four-bar parallel linkage and gauge wheel can adjust the planting of individual seeds in a variable surface to improve sowing depth uniformity (Hu, 1996; Xu et al., 2011).

\footnotetext{
*Corresponding author:

Li Yang, China Agricultural University, College of Engineering, Beijing, 100083, China. E-mail: yangli@cau.edu.cn
} 
Two main types of seeder row units have been applied on the North China Plain to date. A row unit without a parallel four-bar linkage and depth gauge wheels cannot meet precise seeding requirements. Another type of seeder has a parallel four-bar linkage and depth gauge wheel for each row, but the depth gauge wheel is generally placed at the rear of the seeder unit to apply pressure to the soil. Both of these row units cannot ensure a uniform sowing depth (Hu, 1996; Jiang, 2000; Li et al., 2015; Zhao et al., 2013). Numerous advanced precision seeders have the ability to maintain a uniform sowing depth; however, these seeders are not economically feasible for use in small fields covered with residue in China (Tao et al., 2012; Xu et al., 2011). This is because their large sizes make them unsuitable for small fields.

Precision planting in a field with residue has become a major problem in China. An appropriate and uniform sowing depth should be ensured while the seeder needs to have an outstanding clearing ability, to avoid being entangled by residue. It was necessary to create a new method or a mechanism to plant corn into soil covered with residue.

The objectives of this study were two-fold: 1) to design a new row unit that would meet the requirements of precision planting, achieving uniform seed spacing and sowing depth in a field with wheat residue, and 2) to evaluate the effects of the depth-control mechanism of a row unit on sowing performance and seed emergence in fields with different amounts of wheat residue.

\section{MATERIALS AND METHODS}

This study was conducted in a research field of China Agricultural University in Hebei Province in the center of the North China Plain in the summer of 2015. The semiarid climate here includes an average annual precipitation rate of $548 \mathrm{~mm}$. The field was covered with wheat residue; the average residue masses prior to corn planting were 0.64 and $0.78 \mathrm{~kg} / \mathrm{m}^{2}$ for the low and high residue plots, respectively (Fig. 1). Table 1 illustrates some physical properties of the soil.

Three depth-control mechanisms were used as described below. First, a new type of row unit with a depth-control mechanism composed of a single-sided gauge wheel was developed to overcome issues related to planting inconsistencies (Fig. 2a). This unit consisted of a parallel four-bar linkage, a V-shape closing wheel, a pneumatic metering device and other parts. The single rubber gauge wheel has a width of $60 \mathrm{~mm}$, much narrower than the traditional wheel, and was designed to work on a furrow
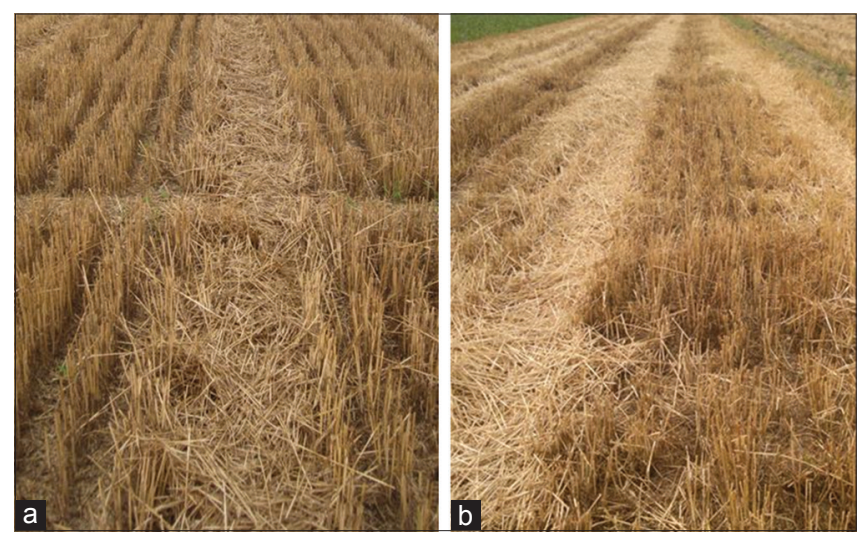

Fig 1. Fields with small and large amount of wheat residue (a) small amount of wheat residue (b) large amount of wheat residue.

Table 1: Soil physical properties for the 0.0 to $0.1 \mathrm{~m}$ depth range

\begin{tabular}{|c|c|c|}
\hline Physical property & $\begin{array}{l}\text { Large residue } \\
\text { amount }\end{array}$ & $\begin{array}{c}\text { Small residue } \\
\text { amount }\end{array}$ \\
\hline Bulk density $\left(\mathrm{Mg} \mathrm{m}^{-3}\right)$ & 1.44 & 1.38 \\
\hline Porosity (\%) & 43.9 & 45.2 \\
\hline $\begin{array}{l}\text { Gravimetric moisture } \\
\text { content }(\% d \cdot b)\end{array}$ & 17.0 & 17.8 \\
\hline $\begin{array}{l}\text { Penetration } \\
\text { resistance }(\mathrm{M} \cdot \mathrm{Pa})\end{array}$ & 1.098 & 1.087 \\
\hline Textural class & \multicolumn{2}{|c|}{ sandy loam } \\
\hline $\begin{array}{l}\text { Residue amount } \\
\left(\mathrm{kg} / \mathrm{m}^{2}\right)\end{array}$ & 0.78 & 0.64 \\
\hline Residue height $(\mathrm{cm})$ & 24.3 & 22.5 \\
\hline
\end{tabular}

created by a fertilizer opener with an acute angle. The fertilizer opener was offset $5 \mathrm{~cm}$ from the seed opener; therefore, a single gauge wheel worked on the furrow created by the fertilizer opener in the front of the seeder; this allowed the machine to try to maintain a uniform sowing depth as well as consistent passing ability. The side gauge wheel floated up and down under the effects of the parallel four-bar linkage on the relief during the sowing operation process to maintain a uniform sowing depth.

Three types of depth-control mechanisms described below were mounted on three row units (including the new unit described above) and were used to conduct three contrasting experimental methods simultaneously on a single seeder in no-till cropland (Fig. 2). All of these units consisted of a parallel four-bar linkage, a double disc opener, a pneumatic metering device and a closing wheel. The greatest difference between the three methods is the position of a gauge wheel on the row unit. A depth-control mechanism on the rear gauge wheel has been widely used on the Huabei Plain of China, with the gauge wheel on the tail of the unit playing the role of a closing wheel as well. Two other units included the single and double-sided gauge wheel(s), respectively, installed parallel to the opener. Sowing depth is the vertical distance from the bottom edge 


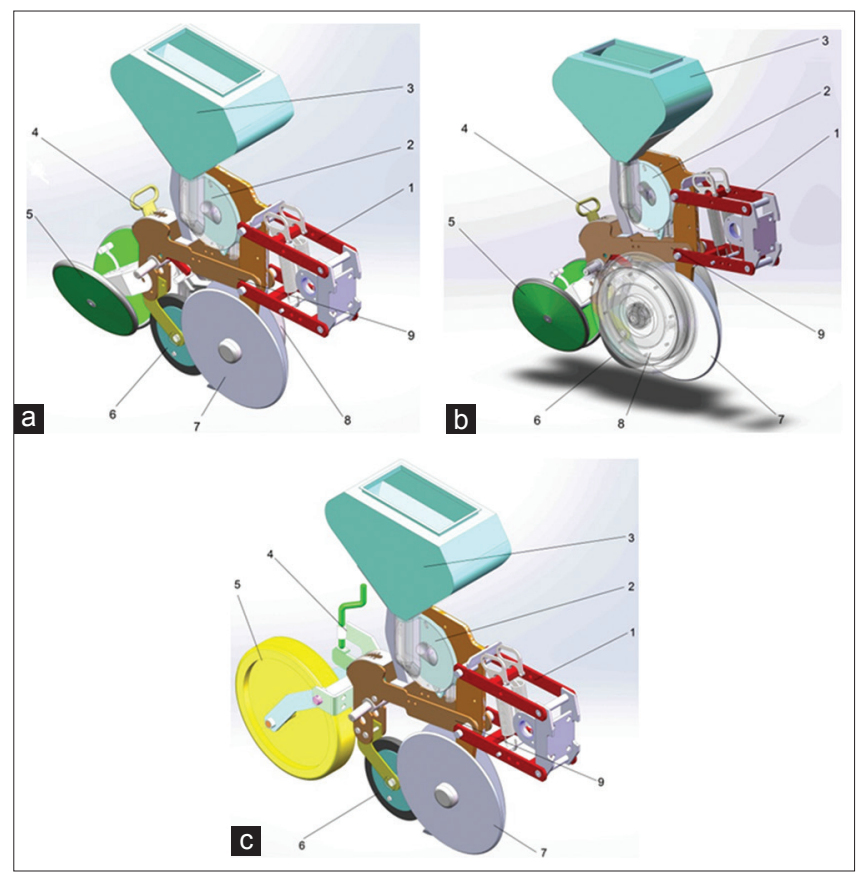

Fig 2. Main structure of seeder units with single-sided gauge wheel, double-sided gauge wheels, and rear gauge wheel 1. Parallel four-bar linkage; 2. seed-metering; 3. seed hopper; 4. regulator of sowing depth; 5. closing wheel; 6 . rubber pressure wheel; 7. double disc opener; 8. copying depth gauge wheel; 9. crossbeam. (a) single-sided gauge wheel (b) double-sided gauge wheels (c) rear gauge wheel.

of the opener to the bottom edge of the gauge wheel, and the depth can be adjusted from 20 to $100 \mathrm{~mm}$ by a handle on the row unit. Double-sided gauge wheels are similar to traditional precision seeders such as the John Deere MaxEmerge (Deere and Co., Moline, IL, USA) and Amazone EDX (Amazonen-Werke H. Dreyer GmbH \& Co., Hasbergen, Germany) systems, but the width of the gauge wheel is narrower in the present experiment.

The study employed a completely randomized block design in a 2 by 3 factorial with six treatments and three replications. The variables were three row of units with depth-control mechanisms of a single-sided gauge wheel adjacent to a seed opener (DM I), a double-sided gauge wheels adjacent to a seed opener (DM II) and a rear gauge wheel to seed opener (DM III) and two residue conditions: small (SAR) and large (LAR) amounts of residue. The variety of corn seed employed here was Taiyu 2\#, a widely used variety on the Huabei Plain, China. The 1000 seed weight, purity, and germination rate of the planted seed were $300 \mathrm{~g}, 96 \%$ and $93 \%$, respectively.

The row units with three types of depth-control mechanisms were mounted on a single no-till precision pneumatic seeder, which consisted of a pneumatic metering device, a row cleaner, a fertilizer applicator and a ground wheel to drive the meters. The pneumatic metering device can work with different shapes of corn seeds within the air pressure of $3 \mathrm{kPa}$ or so with precision seed placement (Shi et al., 2014), while an innovative row cleaner driven by a ground wheel can clean the residue away from the sowing belt (Gao et al., 2014).

The seed metering system on each unit was the same for each unit with a target seed spacing of $0.24 \mathrm{~m}$ in the row and $0.6 \mathrm{~m}$ between rows. The planting population was 69,400 seeds / ha with a planting speed of $4.8 \mathrm{~km} / \mathrm{h}$, while target seed depth was $50 \mathrm{~mm}$.

Seed spacing was measured immediately after planting on a 5 -m length of row on three rows in each plot. Spacing was the distance between two seeds along the row. In addition, the seed emergence and seed spacing were also measured 4, 5, 6, 7, 8, and 12 days after planting. The final spacing data were adopted 12 days after sowing after which seeds no longer emerged.

The sowing uniformity of the distribution pattern along the length of the row was analyzed using the methods described by Kachman and Smith (1995); see that paper for the equations used to calculate the following data. Three indices, multiple (MULI), miss (MISI) and quality of feed (QFI) indices, and precision index (PREC) were measured to evaluate the sowing uniformity.

The actual mean sowing depth (AMSD), seed exposure date (SED), quality of sowing depth index (QSDI) and coefficient of variation of sowing depth (CVSD) were used to quantify the distribution of sowing depth. AMSD was calculated using the method provided by Ritchie and Hanway (1993); with this method the distance from growing point (stem apex) to the seed was measured, and growing point was $2.5-3.8 \mathrm{~cm}$ below the soil surface, so the sowing depth could be confirmed. SED represents the number of exposed seeds remaining unburied in a $10 \mathrm{~m}$ length of row after a planting attempt was made. The QSDI is the percentage of qualified seeds whose depth is within $\pm 10 \mathrm{~mm}$ of the target depth over the total number of seeds. The CVSD is the sowing depth coefficient of variation using the data which is qualified (China, 2008).

The mean emergence time (MET), emergence rate indices (ERI), and percentage of emergence (PE) was determined using the following equations (Karayel and Ozmerzi, 2002):

$$
\begin{aligned}
& \text { MET }=\frac{\mathrm{N}_{1} \mathrm{~T}_{1}+\mathrm{N}_{2} \mathrm{~T}_{2}+\cdots+\mathrm{N}_{\mathrm{n}} \mathrm{T}_{\mathrm{n}}}{\mathrm{N}_{1}+\mathrm{N}_{2}+\cdots \mathrm{N}_{\mathrm{n}}} \\
& \text { ERI }=\frac{S_{t e}}{M E T} \\
& P E=\frac{S_{t e}}{n}
\end{aligned}
$$


Where $N 1 \ldots n=$ number of seedlings emerging since the time of the previous count, $T 1 \ldots n=$ number of days after sowing, $S_{\text {te }}=$ number of total emerged seedlings per $\mathrm{m}$, and $N=$ number of seeds sown per $\mathrm{m}$.

The quality of emergence time index (QETI) is the percentage of viable seeds whose emergence time is within the scope in advance or with one day of delay of MET to the entire group of seeds.

\section{RESULTS AND DISCUSSION}

The effects of depth-control mechanisms and residue amount on seed spacing uniformity, depth uniformity and seed emergence rate were analyzed in this section.

\section{Seed spacing uniformity}

The indices MULI, MISI, QFI and PREC were employed to determine if seed spacing was uniform (Fig. 3a, b, c and d).

With fields having a SAR, the lowest MISI was obtained with the row unit with DM I, followed by DM II and the highest MISI in DM III; these differences were significant (Fig. 3a). The MISI of DM I row unit was also lowest under LAR fields, followed by DM II and the highest MSIS in DM III. The indices were a little higher under the SAR fields, and the MISI of DM III was significantly higher than the other two mechanisms.

The lowest MULI was obtained with the row unit with DM III, while the MULI for the other two units were similar with the SAR fields; no statistical difference was observed between the seeder treatments (Fig. 3b). Meanwhile, this index was almost the same with a LAR.

In the field with a SAR, the row unit with DM I had the highest QFI, which meets the no-till seeder standard published by the Chinese Ministry of Agriculture (China, 2008). The QFI was significantly difference among the three seeder row units with the QFI of DM I $>$ that of DM II and > DM III. The indices were a little higher with a SAR than those with a LAR, and the QFI of DM I was significantly higher than with DM II and DM III (Fig. 3c).

For the PREC data, for both a SAR and a LAR, the row unit with DM III was significantly higher than that of DM I and DM II. They were all below the upper limit for PREC presented by Kachman and Smith (1995), except for DM III with a LAR (Fig. 3d).

Seed spacing uniformity was much better with a SAR based on the MISI, QFI and PREC that with a LAR; this finding agrees with the findings of Raoufat and Matbooei, (2007), who found that with a LAR, the MISI was higher and the QFI was lower. Similarly, Kachman and Smith (1995) reported that the PREC increased as the amount of residue increased.

The seed spacing performance was not affected by only the seed metering device; the other mechanisms of the seeder play an important part in seed transport. The depth control mechanism can affect the seed spacing performance because the furrow opener can affect the uniformity of inter-row seed distribution (Altikat et al., 2013).

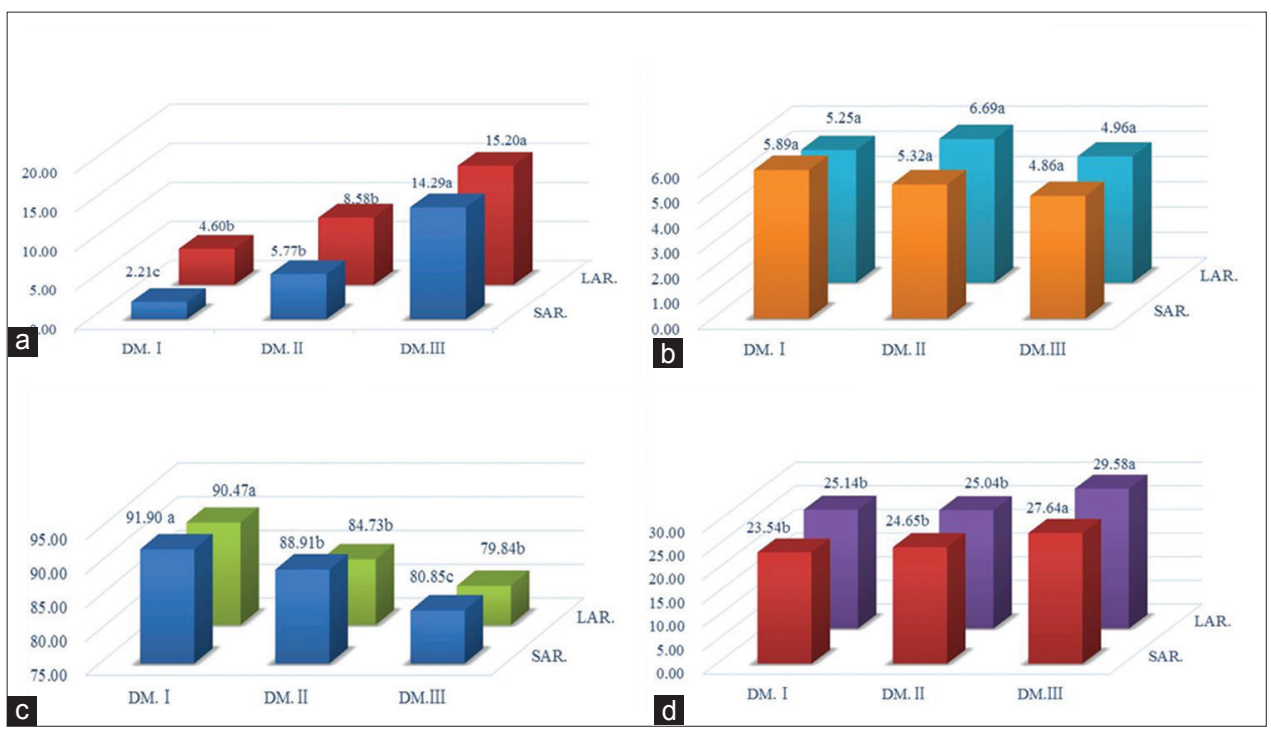

Fig 3. Seeding performance of different depth-control mechanisms DM I, depth-control mechanism of the single-sided gauge wheel adjacent to seed opener; DM II, depth-control mechanism of the double-sided gauge wheels adjacent to seed opener; DM III, depth-control mechanism of the rear gauge wheel to seed opener; LAR, field with a large amount of residue; SAR, field with a small amount of residue. *Different letters on different columns indicate significant difference (a) miss index (MISI) (b) multiple index (MULI) (c) quality of feed index (QFI) (d) precision index (PREC). 
The wide lateral width of the seeder unit with a doublesided gauge wheels made it difficult for the row unit to pass over the residue and the side gauge wheels became blocked with wheat straw. As a result, the seeds could not drop into the furrows from time to time; this affected the emergence rate and seed spacing uniformity. Meanwhile, most of the weight of the row unit with the rear gauge wheel was on the gauge wheel (as well as on the closing wheel) because of a structural defect. This led to excessive force on the soil above the seed and thus reduced the emergence rate and seed spacing uniformity. However, the row unit with a single-sided had an outstanding passing ability in a no-till field with wheat straw residue; at the same time, this row unit has proper gravity distribution because of its reasonably developed structure.

\section{Sowing depth performance}

The parameters used to evaluate the effects of the depthcontrol mechanism and amount of residue on the sowing depth performance were the AMSD (mm), QSDI (\%), $\operatorname{SED}(\mathrm{n} / 10 \mathrm{~m})$ and CVSD (\%).

With a SAR, the AMSD varied significantly between the row units with DM I, DM II and DM III) with the three row units (Fig. 4). Meanwhile, with a LAR the AMSD was significantly different between DM III and the other two depth-control mechanisms. Little difference was observed between the AMSD and target sowing depth, perhaps because the sowing depth was influenced by many factors, and a little error was acceptable.

In this study, in the field with a SAR, the QSDI varied between three row units with DM I, DM II and DM III, respectively (Fig. 5). Meanwhile, with a LAR, the QSDIs were much lower. The row unit with DM I was much better than the other two types of depth-control mechanisms (DM II and DM III) on field conditions with a SAR. Even with a LAR, the row unit with DM I performed best based on the QSDI.

The row unit with DM I also had the lowest CVSD with a SAR, followed by the DM III and DM II type row units; DM I and II were significantly different (Fig. 6). However, the indices were slightly higher and not significantly different with a LAR. CVSD was higher in a field with a LAR than with a SAR. This finding agreed with the findings of Erbach et al. (1986) who declared that the CVSD was higher in fields with more residues. Similarly, Altikat et al. (2013) concluded that the CVSD was much lower in a field with short and standing stubble than in a field with long and flattened stubble. Meanwhile, in the present study the CVSD was varied with different depth-control mechanisms; this is in agreement with the findings of Burris

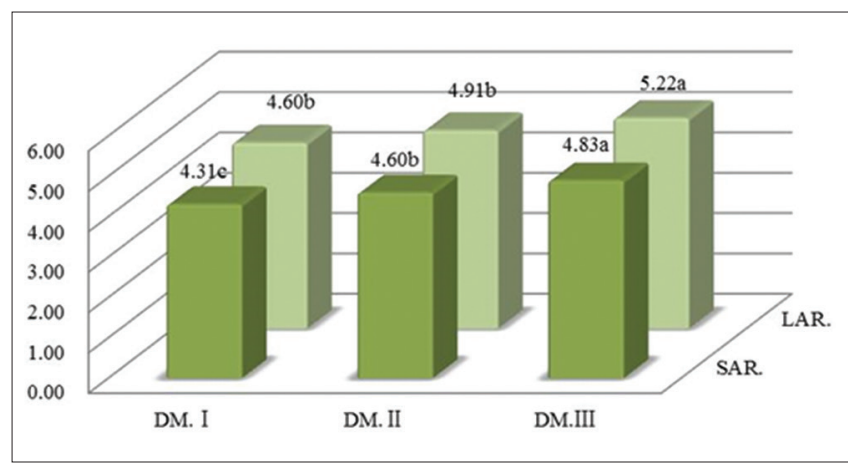

Fig 4. Actual mean sowing depth (AMSD). DM I, depth-control mechanism of the single-sided gauge wheel adjacent to seed opener; DM II, depth-control mechanism of the double-sided gauge wheels adjacent to seed opener; DM III, depth-control mechanism of the rear gauge wheel to seed opener; LAR, field with a large amount of residue; SAR, field with a small amount of residue. * Different letters on different columns indicate significant difference.

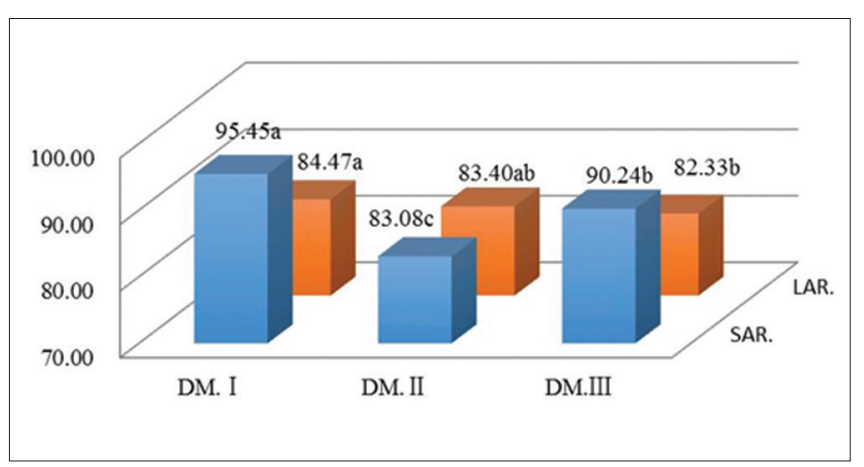

Fig 5. Quality of sowing depth index (QSDI). DM I, depth-control mechanism of the single-sided gauge wheel adjacent to seed opener; DM II, depth-control mechanism of the double-sided gauge wheels adjacent to seed opener; DM III, depth-control mechanism of the rear gauge wheel to seed opener; LAR, field with a large amount of residue; SAR, field with a small amount of residue. *Different letters on different columns indicate significant difference.

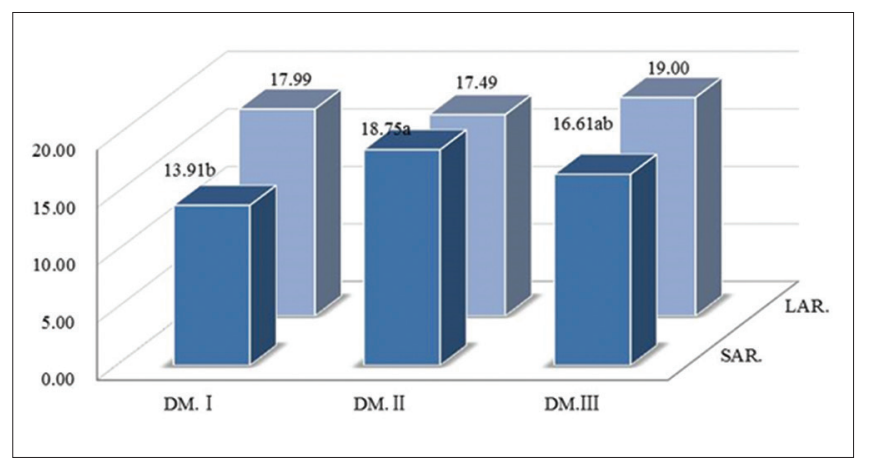

Fig 6. Coefficient of variation of sowing depth (CVSD). DM I, depthcontrol mechanism of the single-sided gauge wheel adjacent to seed opener; DM II, depth-control mechanism of the double-sided gauge wheels adjacent to seed opener; DM III, depth-control mechanism of the rear gauge wheel to seed opener; LAR, field with a large amount of residue; SAR, field with a small amount of residue. *Different letters on different columns indicate significant difference.

(1983) who noted that the location of the gauging wheel would influence the variation in sowing depth. 
In the field with a SAR, the SED was found to be significantly higher with the DM II seeder unit than the DM I and DM III row units. This occurred because the unit with the double-sided gauge wheels was easily blocked up with wheat residue, causing seeds to fail to drop into the furrow successfully. The SED of DM II was much higher in the field with a LAR than with a SAR, while the SED of the DM I and DM III units increased only slightly (Fig. 7). If there was too much wheat residue the SED increased distinctly for the DM II row unit, which agreed with the findings of Nana et al. (2014), who found that the SED increased with an increase in residue covered.

The uniformity of sowing depth of the seeder unit was controlled by the depth-control mechanism. The no-till seeder for the experiment used a depth-control mechanism on each unit so the uniformity of sowing depth was maintained independently for each row. Double-sided gauge wheels easily became blocked and stuck in the straw, so that the gauge wheel could not maintain contact with the ground at all times; this caused to drop into the straw where they could not germinate effectively. Not only did the sowing depth vary dramatically, this situation also caused the seed to be easily left exposed outside of the furrow, which greatly reduced the seed emergence. Compared with the row unit with the side gauge wheel, the row unit with a rear gauge wheel caused profiling lag because the gauge wheel was installed on the rear part of the unit and there was a large distance between it and the opener. As this distance increases, there is a greater possibility that irregular terrain will influence both the depth control and the closing wheel's ability to provide soil to seed contact at all times. The seeder unit with the single-sided gauge wheel (DM I) addressed the deficiencies of the Type II and III depth-control mechanisms; it not only ensured the passing ability but also kept the sowing depth consistent.

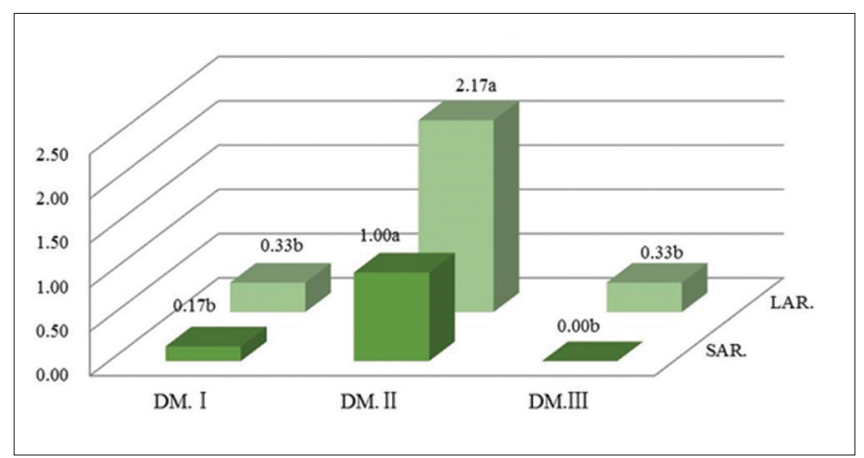

Fig 7. Seed exposure date (SED). DM I, depth-control mechanism of the single-sided gauge wheel adjacent to seed opener; DM II, depthcontrol mechanism of the double-sided gauge wheels adjacent to seed opener; DM III, depth-control mechanism of the rear gauge wheel to seed opener; LAR, field with a large amount of residue; SAR, field with a small amount of residue. *Different letters on different columns indicate significant difference.

\section{Seed emergence}

The MET, QETI, PE and ERI were all considered when determining the emergence performance of the seeds sown using the different row unit depth-control mechanisms used here in fields with two different amounts of residue (Fig. 8a, b, c and d).

In the field with a SAR, the longest MET was obtained using the DM III row unit, followed by DM II and DM I; the performance of the DM I unit was significantly different from DM III (Fig. 8a). Meanwhile, the MET of the field with a LAR was a little longer when compared with the field with a SAR. The MET of the double-sided wheel was longer than that of the single-sided and rear gauge wheel treatments. The may occur because the unit with DM II was easily tangled by residue in the field with a LAR, which led to a shallow sowing depth. In a field lacking sufficient moisture, this situation would extend the emergence time.

The largest QETI was obtained in the plots where the DM I row unit was used, followed by DM II and DM III; in the field with a LAR (Fig. 8b). The row unit with DM I performed significantly better based on the QETI than the other two units. Meanwhile, the QETI was much better in the field with a LAR. The may occur because with an increase in the amount of residue, the row units varied widely on sowing depth and downforce pressure; as a result, the emergence time varied widely. Our findings were similar to those of Erbach et al. (1986), who came to the conclusion that seed emergence was more uniform in fields with few residues. Yakle and Cruse (1983) also found that the presence of too much residue near the seed would influence seedling emergence and lower the emergence index.

When seeds were planted in the field with a SAR, the largest ERI was obtained in the plots with the DM I seeder unit was used, followed by DM II and DM III (Fig. 8c). The ERI decreased with an increase in the amount of residue. The performance of unit with DM I was significantly better than the other units because it had better performance in seed spacing and in creating a uniform sowing depth.

The highest PE in the present study was obtained using the DM I row unit, followed by the DM II and DM III units in the fields with a SAR and a LAR (Fig. 8d). All of these units with different depth-control mechanisms had significantly differences PEs. In addition, the PE decreased slightly with an increase in residue amount. This matched the findings of Kaspar and Erbach (1998), who noted that the emergence rate index decreased as an increasing of amount of residue because residues can be pushed into the soil by coulters or 


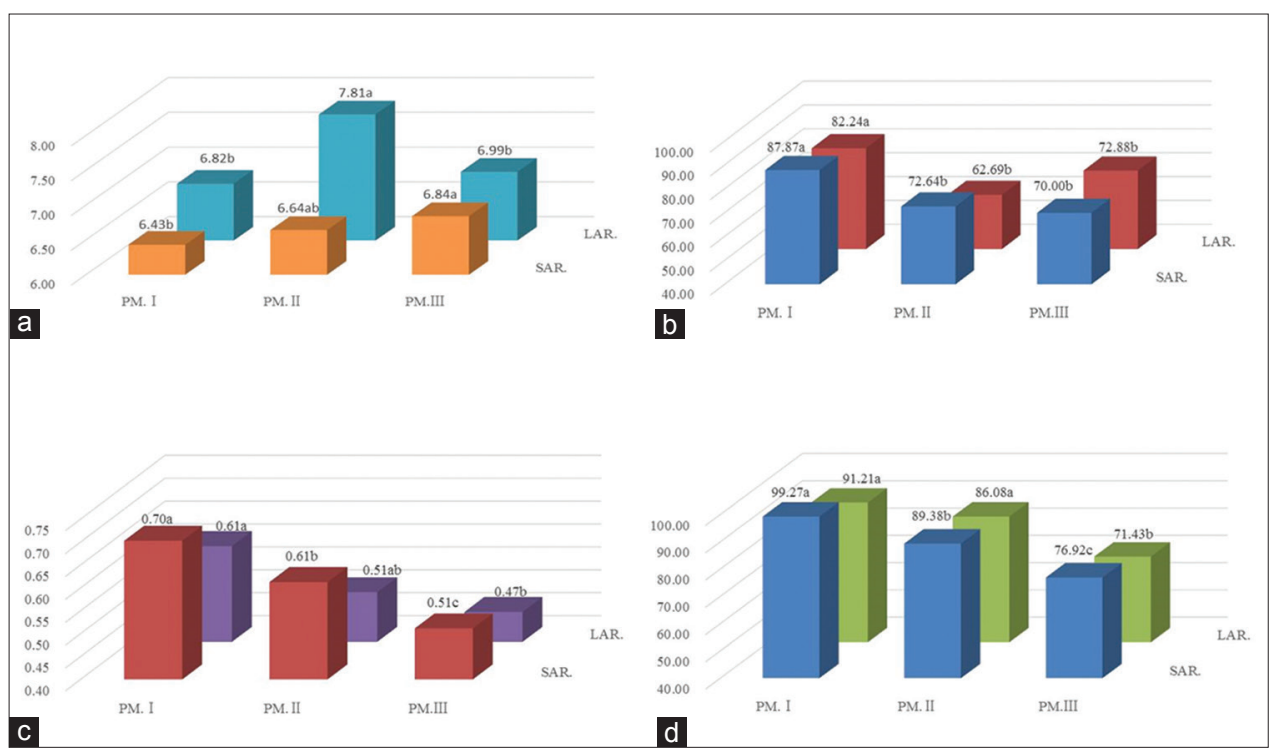

Fig 8. Results related to seed emergence. DM I, depth-control mechanism of the single-sided gauge wheel adjacent to seed opener; DM II, depth-control mechanism of the double-sided gauge wheels adjacent to seed opener; DM III, depth-control mechanism of the rear gauge wheel to seed opener; LAR, field with a large amount of residue; SAR, field with a small amount of residue. *Different letters on different columns indicate significant difference (a) mean emergency time (days after planting) (b) quality of emergence time index (\%) (c) emergence rate index (seeding/m.day) (d) percentage of emergence.

disc openers. The PE of the DM III row unit performed significantly worse than the other two units.

Parameters for seed emergence were similar to sowing depth in that the row unit with the single-sided gauge wheel (DM I) performed best in the field with a SAR.

\section{CONCLUSIONS}

This research demonstrated that the no-till row unit with a single-sided gauge wheel provided better sowing performance and seedling emergence rate than the seeder unit with a double-sided gauge wheels and a rear gauge wheel in a field with wheat residue on the North China Plain. Consequently, the best sowing performance and seed emergence results were obtained by the seeder unit with a single-sided gauge wheel in fields with a SAR. To obtain the most uniform seed spacing, the row unit with a single-sided gauge wheel performed well with a QFI of $91.90 \%$ and PREC of $23.54 \%$; to obtain the most consistent sowing depth with this unit, the QSDI was 95.45\% and the CVSD was $13.91 \%$. Meanwhile, the QETI was $87.87 \%$ based on measuring the emergence time. Most of the indices were much better than the other two no-till row units, as well as better passing ability in field with residue. The depthcontrol mechanism with a single-sided gauge wheel can meet the requirements of no-till planting for corn on the North China Plain. Corn no-till seeder with this new depthcontrol mechanism should be produced and promoted in this area.

\section{ACKNOWLEDGEMENTS}

This research was supported by the Special Fund for Agroscientific Research in the Public Interest (201503116); and the Special Fund for Agro-scientific Research in the Public Interest (201503117); and the China Agriculture Research System (Grant No. CARS-02).

\section{Authors contributions}

Tao Cui and Bingxin Yan were involved in conducting the experiment, Xiantao He and Dandan Han were involved in analyzing test data, Dongxing Zhang and Jiantao Wei were involved in designing the experiment, Jiantao Wei was involved in revising the language of this manuscript, Li Yang was the project director and guided the whole experiment.

\section{Abbreviations used}

AMSD, actual mean sowing depth; CVSD, coefficient of variation of depth; DM I, depth-control mechanism of the single-sided gauge wheel adjacent to seed opener; DM II, depth-control mechanism of the double-sided gauge wheels adjacent to seed opener; DM III, depth-control mechanism of the rear gauge wheel to seed opener; ERI, emergence rate indices; LAR, large amount of residue; MET, mean emergence time; MISI, miss index; MULI, multiple index; PE, percentage of emergence; PREC, precision index; QETI, quality of emergence time index; QFI, quality of feed index; QSDI, quality of sowing depth index; SED, seed exposure rate; SAR, small amount of residue. 


\section{REFERENCES}

Altikat, S., A. Celik, and Z. Gozubuyuk. 2013. Effects of various notill seeders and stubble conditions on sowing performance and seed emergence of common vetch. Soil Till. Res. 126: 72-77.

Burris, J. S. A. D. 1983. Corn Establishment under Various Tillage Systems. Iowa Agric. and Home Econ. Exp. Stn. Journal Paper No. J-11201.

Çeli $\square$ k, A. 2009. The Factors Affecting Performance of Direct Seeding Machines. Ziraat Fakültesi Dergisi, Atatürk Üniversitesi, p. 101-108.

Chen, Y., F. V. Monero, C. Cavers, D. Lobb, and S. Tessier. 2004. Effects of six tillage methods on residue incorporation and crop performance in a heavy clay soil. Trans. ASAE. 47: 1003-1010.

China, N. S. O. P. 2008. Operating Quality for No-Tillage Maize Planter. In: Standards Press Of China, Beijing.

Erbach, D. C., R. M. Cruse, T. M. Crosbie, D. R. Timmons, T. C. Kaspar, K. Potter. 1986. Maize response to tillage-induced soil conditions. Trans. ASAE. 29: 690-695.

Gan, Y., E. H. Stobbe. 1995. Effect of variations in seed size and planting depth on emergence, infertile plants, and grain yield of spring wheat. Can J Plant Sci. 75: 565-570.

Gao, H., W. Li, and H. Li,. 2003. Conservation tillage technology with Chinese characteristics. Trans. Chin. Soc. Agric. Eng. 19(03): 1-4

Gao, N., D. Zhang, L. Yang, T. Cui, C. A. University. 2014. Design of anti-blocking mechanism combined driven divider with passive residue separating device. Chin. Soc. Agric. Mech. 45: 84-85.

Hendrix, P. F., A. C. Peterson, M. H. Beare, D. C. Coleman. 1998. Long-term effects of earthworms on microbial biomass nitrogen in coarse and fine textured soils. Appl Soil Ecol. 9: 375-380.

$\mathrm{Hu}, \mathrm{H}$. 1996. Study on designing and testing of the drill unit with individual profiling press wheel. Chin. Soc. Agric. Mech. 61: 233-287.

Jiang, J. 2000. Study on the working performance of the no-tillage planter unit. Chin. Soc. Agric. Mech. 16: 64-66.

Kachman, S. D., J. A. Smith. 1995. Alternative measures of accuracy in plant spacing for planters using single seed metering. Trans. ASAE. 38: 379-387.

Karayel, D., A. Ozmerzi. 2002. Effect of tillage methods on sowing uniformity of maize. Can. Biosyst. Eng. 44: 2-23.

Kaspar, T. C., D. C. Erbach. 1998. Improving stand establishment in no-till with residue-clearing planter attachments. Trans. ASAE. 41: 301-306.

Krall, J. M., H. A. Esechie, R. J. Raney, S. Clark, G. TenEyck, M. Lundquist, N. E. Humburg, L. S. Axthelm, A. D. Dayton, Vanderlip, R. L. 1977. Influence of within-row variability in plant spacing on corn grain yield. Agron. J. 69: 797-799.

Li, Y., Z. Rui, G. Nana, C. Tao, L. Quanwei and Z. Dongxing. 2015. Performance of no-till corn precision planter equipped with row cleaners. Int. J. Agr. Biol. Eng. 8(5): 15-25.

Nana, G., Z. Dongxing, Y. Li and C. Tao. 2014. Design of anti-blocking mechanism combined driven divider with passive residue separating device. Chin. Soc. Agric. Mech. 30(5): 10-18.

Raoufat, M. H and A. Matbooei. 2007. Row cleaners enhance reduced tillage planting of corn in Iran. Soil Till. Res. 93: 152-161.

Ritchie, S. W and J. J. Hanway. 1993. How a Corn Plant Develops. Ames, IA (USA), lowa State University, p. 20 Special Report. No. 48.

Shi, S., D. Zhang, L .Yang, T. Cui, R. Zhang and X. Yin. 2014. Design and experiment of pneumatic maize precision seed-metering device with combined holes. Trans. Chin. Soc. Agric. Eng. 30: 10-18.

Staggenborg, S. A., R. K. Taylor and L. D. Maddux. 2004. Effect of planter speed and seed firmers on corn stand establishment. Appl Eng Agric. 20: 573-580.

Tao, C and D. Zhang, Y. Li. 2012. Design and experiment of collocated-copying and semi-low-height planting-unit for corn precision seeder [J]. Trans. Chin. Soc. Agric. Eng. 28: 18-23.

Van Donk, S. J., D. L. Martin, S. Irmak, S. R. Melvin, J. L. Petersen and D. R. Davison. 2010. Crop residue cover effects on evaporation, soil water content, and yield of deficit-irrigated corn in westcentral Nebraska. Trans. ASABE. 53: 1787-1797.

Xu, J., Y. Xie and T. Xu. 2011. The present technic status and developing tendency of the domestic and abroad drill. J. Agric. Mech. Res. 33: 234-237.

Yakle, G. A and R .M. Cruse. 1983. Corn plant residue age and placement effects upon early corn growth. Can J Plant Sci. 63: 871-877.

Zhao, S., E. Jiang, Y. Yan, Y. Yang and B. Tian. 2013. Design and motion simulation of opener with bidirectional parallelogram linkage profiling mechanism on wheat seeder. Trans. Chin. Soc. Agric. Eng. 29: 26-32. 